\title{
A STUDY TO COMPARE THE OUTCOME OF SELECTED SURGICAL PROCEDURES FOR PROXIMAL URETERAL STONE TREATMENT AT CARE INSTITUTE OF MEDICAL SCIENCES, HYDERABAD FROM MAY 2011 TO APRIL 2013
}

\author{
Ch. Koteswaramma1, Mussar ${ }^{2}$
}

${ }^{1}$ Associate Professor, Department of Community Medicine, Rajeev Gandhi Institute of Medical Sciences, Adilabad.

${ }^{2}$ Postgraduate Student, Department of Urosurgery, Care Institute of Medical Sciences, Hyderabad.

\section{ABSTRACT}

\section{BACKGROUND}

Urinary stone disease causes morbidity, thus lead to loss of wages and economy. The estimated prevalence is $2 \%-3 \%$ with lifetime risk of $12 \%$ for white males and $5 \%-6 \%$ for white females, and lifetime recurrence rate is $50 \%$. The increased incidence of urinary stones in the industrialised world is associated with improved standards of living (mainly including the high dietary intake of proteins and minerals). Treatment outcome mainly depends upon clinical, anatomic, stone factors and especially on available equipment, expertise and cost. Stone diameter $\geq 4 \mathrm{~mm}$ is associated with a progressive decrease in the spontaneous passage rate, which is unlikely with stones $\geq 10 \mathrm{~mm}$ in diameter. Proximal ureteral stones are also less likely to pass spontaneously, so they are often removed by surgical procedures.

Objectives- 1). To assess the prevalence and risk factors of Upper urinary tract calculi among Genitourinary surgical department patients, Care Institute of Medical Sciences, Hyderabad from May 2011 to April 2013; 2). To compare the outcome of the selected treatment procedures in the same study population and study setting and study period.

\section{MATERIALS AND METHODS}

This prospective cohort study conducted from August 2011 to July 2013 among 90 eligible proximal ureteral stone sufferers by grouping them into Group 1 (PCNL- Percutaneous nephrolithotomy), Group 2 (URSL- Ureteroscopic lithotripsy) and Group 3 (ESWL- Extracorporeal shock wave lithotripsy) as per their type of treatment. After collection of the personal, social, economic and clinical and lab tests information, we gave the selected treatment and followed them up to 3 months. During followup if stone fragments are retained, then we performed additional procedures and treated the complications if any. Lastly, outcome comparison between 3 treatment groups was done.

\section{RESULTS}

Study has shown $35 \%$ prevalence of the renal calculi, out of which about $75.71 \%$ of them were of proximal ureteral calculi sufferers who have shown bimodal age distribution at $\geq 30$ and $\geq 50$ years. Overall, stone free rate after the initial and additional treatment procedures was 100\% in PCNL group, but $96.67 \%$ and $93.33 \%$ in URSL and ESWL groups irrespective of the stone size. Mean cost treatment was high with PCNL procedure than others. Mean length of hospital stay was high in URSL followed by ESWL and PCNL. The retained ureteral stone fragments were high among ESWL group with 33.33\%, whereas highest numbers of complications were seen in URSL group followed by ESWL and PCNL groups.

\section{CONCLUSION}

Based on above observations, we concluded the study by saying that PCNL is cost effective method for proximal ureteral calculi treatment than other two.

\section{KEYWORDS}

Proximal Ureteral Stones, Percutaneous, Ureteroscopy, Extracorporeal, Nephrolithotomy, Retained Fragments and Renal Failure or Obstruction, etc.

HOW TO CITE THIS ARTICLE: Koteswaramma Ch., Mussar. A study to compare the outcome of selected surgical procedures for proximal ureteral stone treatment at Care Institute of Medical Sciences, Hyderabad from May 2011 to April 2013. J. Evolution Med. Dent. Sci. 2017;6(56):4177-4182, DOI: 10.14260/Jemds/2017/905

\section{BACKGROUND}

Urinary stone disease is a major public health care problem causing morbidity, loss of workdays and economy. Urinary

Financial or Other, Competing Interest: None.

Submission 14-02-2017, Peer Review 16-03-2017,

Acceptance 22-03-2017, Published 13-07-2017.

Corresponding Author:

Dr. Ch. Koteswaramma,

Associate Professor,

Department of Community Medicine,

Rajeev Gandhi Institute of Medical Sciences,

Adilabad, Telangana.

E-mail: chkoti.eshwari@gmail.com

DOI: $10.14260 /$ jemds $/ 2017 / 905$

\section{(c) $($ ) $\ominus$}

stones are the third most common affliction of the urinary tract, exceeded only by urinary tract infections and pathologic conditions of the prostate.[1] The disease is very common among men and women with estimated prevalence among the population of $2-3 \%$ and an estimated lifetime risk of $12 \%$ for white males ${ }^{[2]}$ and $5-6 \%$ for white females. ${ }^{[2]}$ The lifetime recurrence rate is approximately $50 \%{ }^{[3]}$ The interval between recurrences is variable with approximately $10 \%$ within one year, $35 \%$ within five years and $50 \%$ within 10 years.[2] The increased incidence of urinary stones in the industrialised world is associated with improved standards of living (mainly including the high dietary intake of proteins and minerals) as well as with race, ethnicity and region of residence. ${ }^{[4]}$ A seasonal variation is also seen with high 
urinary calcium oxalate saturation in men during summer and in women during early winter.[5] Stones form twice as often in men as in women. The peak age in men is 30 years; women have a bimodal age distribution with peaks at 35 and 55 years. ${ }^{[6]}$

The factors that used to determine the optimal treatment for patients with renal or ureteral calculi are grouped into four categories: 1). Stone factors: location, size, composition, presence and duration of obstruction, 2). Clinical factors: symptom severity, patient's expectations, associated infection, obesity, coagulopathy, hypertension and solitary kidney, 3). Anatomic factors: horseshoe kidney, ureteropelvic junction obstruction and renal ectopia, and 4). Technical factors: available equipment, expertise and cost.[7] The likelihood of spontaneous passage of renal stone is related to both size and composition of the stone. Most stones $\leq 4 \mathrm{~mm}$ in diameter pass spontaneously. Stone diameter $\geq 4 \mathrm{~mm}$ is associated with a progressive decrease in the spontaneous passage rate, which is unlikely with stones $\geq 10 \mathrm{~mm}$ in diameter.[8] Proximal ureteral stones are also less likely to pass spontaneously. In a patient who has a newly diagnosed ureteral stone $\leq 10 \mathrm{~mm}$ and whose symptoms are controlled, observation with periodic evaluation is an option for medical therapy to facilitate stone passage during observation period. Patients who elect for an attempt to spontaneous passage of medical expulsive therapy should have well controlled pain, no clinical evidence of sepsis and adequate renal functional reserve.[7] This present analytical cohort study was taken to compare the outcome between three selected surgical treatment procedures, as there was not enough data regarding the cost effective and benefit surgical treatment procedures in Indian scenario. In order to advice the urosurgeons to choose that best method for fast relief to the patient with minimum efforts and complications, so as to improve the community morbidly and to improve community economic status.

\section{MATERIALS AND METHODS}

\section{Study Objectives}

1. To assess the prevalence and risk factors of upper urinary tract calculi among Genitourinary Surgical Department patients, Care Institute of Medical Sciences, Hyderabad from May 2011 to April 2013.

2. To compare the outcome of the selected treatment procedures in the same study population and study setting and study period.

\section{Study Setting}

Care Institute of Medical Sciences is a well-organised corporate medical college and hospital with an average 1200 OPD patients/day and having 500 beds. Its Urosurgery Department is one of the best departments in treating these renal patients; it treats minimum 5 and maximum 50 outpatients/day among which we admit 2 to 5 patients/day either for observation or for initiating the major treatment. Department provides medical assistance to those who have the upper ureteral stone of 4 or less $\mathrm{mm}$ and administer emergency surgical treatment of those who come with sepsis and impaction along with medical therapy and also who failed to pass stone spontaneously after medical treatment, and those who opted for immediate cure from the renal stone.

\section{Study Design and Period}

Prospective cohort study from August 2010 to July 2012.

\section{Study Sample}

90 patients who were fitting into our eligible criteria during the study period.

\section{Sampling Technique}

We grouped and allotted the study subjects into Group 1 (PCNL), Group 2 (URSL) and Group 3 (ESWL) in a sequential order of their type of treatment.

\section{Selection of Study Population \\ Inclusion Criteria}

Patients with proximal ureteral (renal) colic $<10 \mathrm{~mm}$ and $\geq$ $10 \mathrm{~mm}$ stone size and with or without mild impaction or hydronephrosis. And who gave the consent to participate in the study including followup period of 6 months.

\section{Exclusion Criteria}

Those with mid and distal ureteral stone or proximal stone with large impaction or moderate-to-severe hydronephrosis or pyonephrosis or sepsis, bilateral obstruction or unilateral obstruction in single kidneys.

\section{Methodology}

After study hypothesis conception, we proceeded for review of the available literature and fixed our aims and objectives and protocol was drawn including time schedule, sample size, sampling technique and inclusion and exclusion criteria for selection of the study population. Next, we took permission from Care Hospital Ethical Committee. Then study tool was finalised by a pilot study; with this we recorded all required personal, social, economic and clinical and all other required laboratory investigation details from the eligible patients. Then we grouped them into 1, 2, 3 according to the type of treatment that they were going to receive, i.e. Group 1 (PCNL), Group 2 (URSL) and Group 3 (ESWL); this process was continued. At the end of 18 months we had 30, 31 and 33 proximal ureteral stone sufferers gave informed written consent to participate in the study, but we round them to 30 in each treatment group (PCNL, ESWL and URSL) for easy analysis. After giving the respective treatment we followed once in a month up to 3 months for evaluation of the outcome of those procedures by oral questions, clinical examination and KUB imaging studies. If recurrence or retainment of stone occurred during followup period we did additional procedures as per willingness of the patient, i.e. either to undergo additional surgical procedure or conservative treatment including spontaneous passage of stone. At the end of the day, we used to enter the data in Microsoft Excel master sheet. Lastly, we analysed results and compared with the help of statistical measures and tests values. Then we discussed our results with few national and international studies, which were available during the study period and concluded the study with the key points and recommendations.

\section{RESULTS}

In the present study, we collected the primary data from 389 patients at OPD for 18 months period to whom we performed all the required clinical and laboratory investigations. And 
identified that $35 \%(140 / 389)$ of them were suffering from ureteral calculi. But the estimated prevalence among general population it was only $2-3 \%{ }^{[7]}$ This deviation may be due to total variation in the geographic and ethnicity of study population. And about $75.71 \%(106 / 140)$ of identified renal calculi sufferers were of proximal type and the remaining $7.14 \%(10 / 140), 17.14 \%(24 / 140)$ were mid and distal ureteral stones respectively. Among total proximal ureteral stones, about $6.66 \%$ stones with $<10 \mathrm{~mm}$ size had spontaneous passage, whereas INA study done by J Stuart Wolf, Jr, MD, FACS with $<7 \mathrm{~mm}$ size stone; spontaneous stone passage rate was up to $25 \% .{ }^{[7]}$ Only 94 proximal ureteral stone sufferers gave informed written consent to participate in the study, but we round them to 30 in each treatment group (PCNL, ESWL and URSL) for easy analysis.

\section{Demographic and Risk Factors[1],[6]}

The proximal ureteral stone sufferers have shown bimodal age distribution at $\geq 30$ and $\geq 50$ years with significantly high among $\geq 30$ years' age group (90\%) than $<30$ years irrespective of the type of gender with $p<0.08$ (Figure 1).

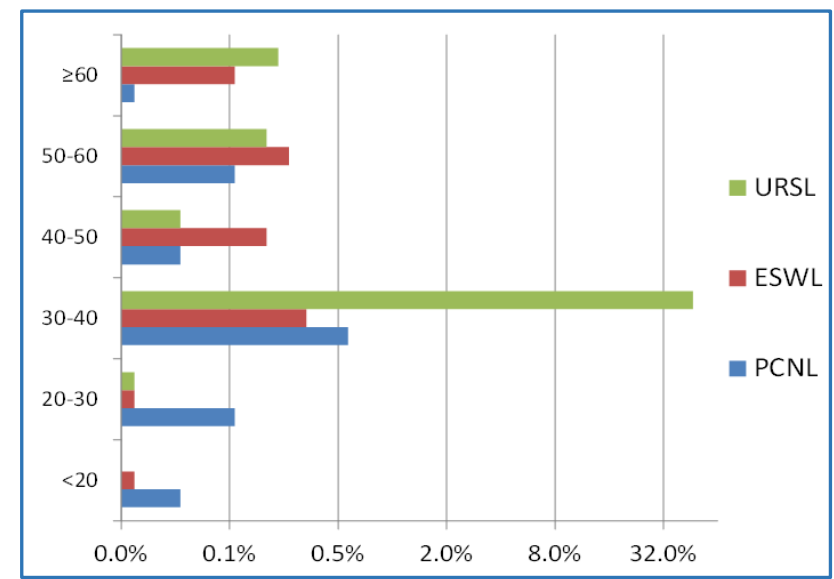

Figure 1. Age Wise Distribution of the Study Population according to Type of Treatment received for the Proximal Ureteral Stones

It is also observed that the overall prevalence of proximal stone rate among male was more than twice the female population with $70 \%$ and $30 \%$ respectively (Figure 2). And almost similar results were observed by Menon M, Parulkar BC, Drash GW, et al and J Stuart Wolf.[1],[7]

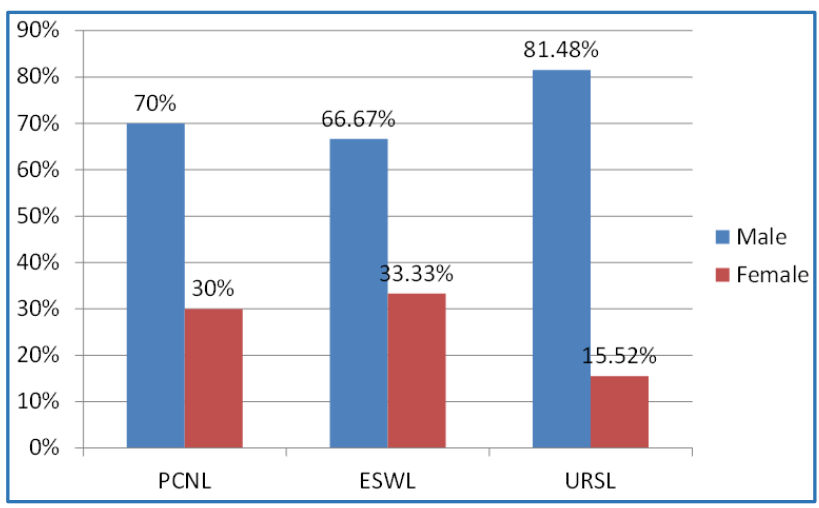

Figure 2. Distribution of the Study Population according to Gender and Type of Treatment received for the Proximal Ureteral Stones
The upper ureteral stone prevalence was not high in those who do not do physical exercise for 3 - 5 days/week irrespective of the treatment.

The PCNL acceptors were significantly high among $<40$ years' age group with $76.67 \%$ followed by URSL acceptors with $55.56 \%$ acceptance level.

This may be because their desire to get rid of their health problem cent percent with no or minimal complications, so that can resume their duties either towards their career and income than other age groups. Whereas ESWL acceptors were high in 40 or more years' age group with acceptance level of $60 \%$ and this observed difference in age distribution was significant $\left\{X^{2}=13.20(p<0.001), d f=2,95 \%\right.$ confidence intervals\}.

\section{DISCUSSION}

The present study shows that significantly more number of PCNL treatment acceptors belonged to upper socioeconomic class followed by other economic classes and most of the ESWL and URSL treatment acceptors were from middle and lower socio-economic classes $\left\{\mathrm{x}^{2}=5.54(\mathrm{p}<0.06)\right.$ at $\mathrm{df}=2$ and at $95 \% \mathrm{CF}$. This difference may be due to high level of paying capacity of PCNL users than ESWL and URSL users.

Our study revealed that more number of surgical treatment acceptors belonged to $10^{\text {th }}$ and above studied population with $86.67 \%, 81.11 \%$ and $71.11 \%$ of PCNL, ESWL and URSL treatment acceptors respectively. And the remaining were of $<9^{\text {th }}$ class studied population including illiterates. But this educational difference was not statistically significant $\left\{\mathrm{x}^{2}=2.5(\mathrm{p}>0.28)\right.$ at $\mathrm{df}=2$ and at $\left.95 \% \mathrm{CF}\right\}$. This high acceptance of PCNL procedure may be because of increased level of understanding among $10^{\text {th }}$ and above studied population.

The study also shows that more number of surgical treatment acceptors belonged to professional, semi-skilled occupations with $66.66 \%, 56.67 \%$ and $53.33 \%$ of PCNL, ESWL and URSL treatment respectively. The remaining was of unskilled, clerical, student or unemployed subjects. But this occupational difference was not statistically significant $\left(\mathrm{x}^{2}=\right.$ $1.19(\mathrm{p}>0.56)$.

Our study observed that more number of surgical treatment acceptors were those who consume nonvegetarian daily or 3 - 5/week belongs with 73.34\%, 66.67\% and $66.67 \%$ of PCNL, ESWL and URSL treatment respectively than who do not or consume non-vegetarian less than 2 times a week. But this difference was not significant $\left(x^{2}=1.19(p>\right.$ $0.56)$.

The present study found that less number of surgical treatment acceptors were those who do physical exercise daily or 3 - 5 days/week with $6.66 \%, 13.32 \%$ and $8.88 \%$ of PCNL, ESWL and URSL treatment respectively than the others. But this difference was not significant $\left(x^{2}=0.81(p>\right.$ $0.66)$.

Our study discovered that the prevalence of total comorbidities among the study groups was $38.89 \%$, i.e. hypertension and diabetes mellitus with $17.78 \%$ and $21.11 \%$ respectively. And the prevalence of total renal failure cases in them was $31.11 \%$. 
Treatment Outcome

Stone Free Rate (Tables 1 - 3).

\begin{tabular}{|c|c|c|}
\hline \multirow{2}{*}{ Treatment Group } & \multicolumn{2}{|c|}{$\begin{array}{c}\text { Stone Free Rate on Initial } \\
\text { (Primary) Treatment }\end{array}$} \\
\cline { 2 - 3 } & Yes & No \\
\hline PCNL $(\mathrm{n}=30)$ & $14(100 \%)$ & $0(0 \%)$ \\
\hline ESWL $(\mathrm{n}=30)$ & $9(75 \%)$ & $3(25 \%)$ \\
\hline URSL $(\mathrm{n}=30)$ & $14(93.33 \%)$ & $1(13.33 \%)$ \\
\hline \multicolumn{2}{|c|}{ Table 1. Distribution of Study Population } \\
according to Stone Free Rate after Initial \\
Surgical Procedures for < 10 mm \\
Proximal Ureteral Stones
\end{tabular}

The Table 1 was showing that stone free rate achieved after initial treatment for $<10 \mathrm{~mm}$ upper ureteral stone was high (100\%) among PCNL group, whereas it was $93.33 \%$ and $75 \%$ in URSL and ESWL groups respectively.

\begin{tabular}{|c|c|c|}
\hline \multirow{2}{*}{ Treatment Group } & \multicolumn{2}{|c|}{$\begin{array}{c}\text { Stone Free Rate on } \\
\text { Initial (Primary) Treatment }\end{array}$} \\
\cline { 2 - 3 } & Yes & No \\
\hline PCNL $(\mathrm{n}=30)$ & $14(87.50 \%)$ & $2(12.5 \%)$ \\
\hline ESWL $(\mathrm{n}=30)$ & $11(61.11 \%)$ & $7(38.88 \%)$ \\
\hline URSL $(\mathrm{n}=30)$ & $12(80 \%)$ & $3(20 \%)$ \\
\hline Table 2. Distribution of Study Population according \\
to Stone Free Rate after initial Surgical \\
Procedures for $\geq \mathbf{1 0}$ mm Proximal Ureteral Stones \\
\hline
\end{tabular}

And Table 2 was showing that stone free rate achieved on initial treatment for $\geq 10 \mathrm{~mm}$ proximal ureteral stones was high (87.5\%) among PCNL treatment group followed by URSL and ESWL treatment groups with $80 \%$ and $61.11 \%$ respectively. But these results were not correlating with the Kumar and Colleagues who achieved an $86 \%$ initial success rate $(\mathrm{n}=86)$ in patients who had impacted proximal ureteral stones. ${ }^{[8]}$ And Maheshwari and Colleagues who addressed 23 proximal ureteral stones, all impacted and greater than 1.5 cm reported $100 \%$ success and no complications.[9] Goel and Associates also described complete stone eradication in 65 of 66 patients who had impacted proximal ureteral stones greater than $1.5 \mathrm{~cm} \cdot{ }^{[10]}$

\begin{tabular}{|c|c|c|c|}
\hline \multirow{2}{*}{$\begin{array}{c}\text { Treatment } \\
\text { Group }\end{array}$} & \multicolumn{3}{|c|}{$\begin{array}{c}\text { Stone Free Rate Irrespective } \\
\text { of the Stone Size }\end{array}$} \\
\cline { 2 - 4 } & $\begin{array}{c}\text { Initial } \\
\text { Treatment }\end{array}$ & $\begin{array}{c}\text { Retreatment } \\
\text { (Additional } \\
\text { Procedures*) }\end{array}$ & $\begin{array}{c}\text { Both } \\
\text { Treatments }\end{array}$ \\
\hline PCNL (n = 30) & $28(93.33 \%)$ & $2(6.67 \%)$ & $30(100 \%)$ \\
\hline ESWL (n = 30) & $20(66.67 \%)$ & $8(26.67 \%)$ & $28(93.33 \%)$ \\
\hline URSL (n = 30) & $26(86.67 \%)$ & $3(10 \%)$ & $29(96.66 \%)$ \\
\hline \multicolumn{3}{|c|}{$\begin{array}{c}\text { Table 3. Distribution of the Study Population } \\
\text { according to the overall Stone Free Rate after } \\
\text { Initial and Additional Procedures } \\
\text { irrespective of the Stone Size }\end{array}$} \\
\hline
\end{tabular}

Chi-Square test $=7.91(p>0.019)$ at $\mathrm{df}=2$ and at $95 \%$ confidence intervals. *Additional procedures include either surgical or conservative therapy (Conservative therapy includes chemotherapy or spontaneous passage).

The Table 3 was revealing that at the end of the initial treatment, the stone free rate irrespective of the stone size was significantly high $93.33 \%\left(\mathrm{X}^{2}\right.$ test value $\left.=7.91, \mathrm{p}<0.019\right)$ among PCNL treatment group followed by URSL and ESWL treatment groups with $86.67 \%$ and $66.67 \%$ respectively irrespective of the stone size. ${ }^{[8]}$ And retreatment rate was very high in ESWL group (26.66\%) followed by URSL (10\%) and PCNL (6.67\%) groups. And overall stone free rate after the initial and additional treatment procedures irrespective of the stone size was $100 \%$ in PCNL group, but $96.67 \%$ and 93.33\% in URSL and ESWL groups (Figure 3).[11]

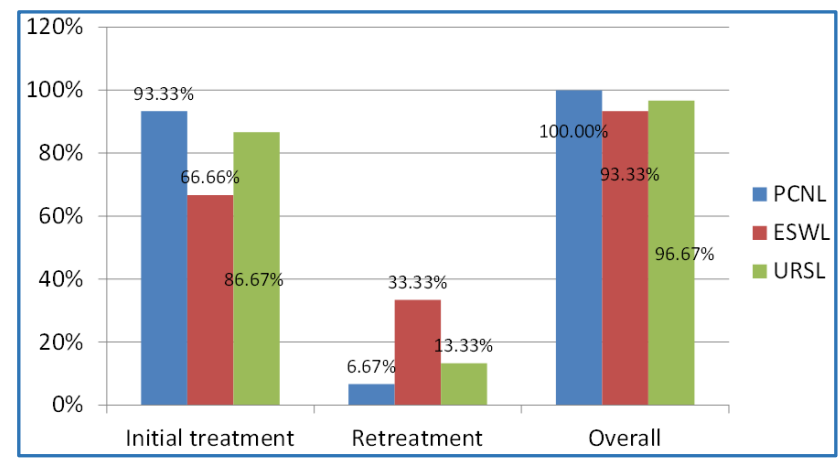

Figure 3. Distribution of the Study Population according to the overall Stone Free Rate at all Stages of Treatment irrespective of the Size of the Proximal Ureteral Stone

Cost and Duration of the Treatment (4 and 5 Tables)

\begin{tabular}{|c|c|c|c|}
\hline $\begin{array}{c}\text { Cost of } \\
\text { Treatment }\end{array}$ & PCNL & ESWL & USRL \\
\hline $\begin{array}{c}\text { Total } \\
\text { Expenditure }\end{array}$ & 1058000 & 778000 & 935000 \\
\hline Mean Cost & 35266.67 & 25933.33 & 31166.67 \\
\hline Variance & 1.26 & 17.32 & 4.4 \\
\hline SED & 1.12 & 4.16 & 2.11 \\
\hline ANOVA Test & $\begin{array}{c}\text { Calculated 'F' Statistic= 2.78 (3.07 table } \\
\text { value) P > 0.05 at 95\% Confidence Intervals } \\
\text { and df= 87. Not significant. }\end{array}$ \\
\hline & $\begin{array}{r}\text { Table 4. Distribution of the Study Population } \\
\text { according to the Cost of Treatment }\end{array}$ \\
\hline
\end{tabular}

The Table 4 shows that the observed difference between the Standard Error of Difference (SED) in mean cost treatment for removal of proximal ureteral stones was high among PCNL treatment group than other treatment groups, but this difference was statistically not significant at $95 \%$ of confidence limits and at 87 degrees of freedom as per Analysis of Variance Test ( $p>0.05)$.[9],[12]

\begin{tabular}{|c|c|c|c|}
\hline $\begin{array}{c}\text { Duration of } \\
\text { Hospital Stay } \\
\text { (Days) }\end{array}$ & PCNL & ESWL & USRL \\
\hline Total Duration & 94 & 52 & 71 \\
\hline Mean Length & 3.1 & 1.7 & 2.36 \\
\hline Variance & 0.12 & 0.68 & 0.24 \\
\hline SED & 0.34 & 0.82 & 0.49 \\
\hline \multicolumn{3}{|c|}{$\begin{array}{c}\text { Calculated 'F' Statistic= } 44.12 \\
\text { ANOVA Test }\end{array}$} & $\begin{array}{c}\text { confidence intervals at } \\
\text { Df= 87, Significant }\end{array}$ \\
\hline \multicolumn{2}{|c|}{ Table 5. Distribution of Study Subjects } \\
according to the Duration of Hospital Stay \\
\hline
\end{tabular}


Above Table 5 showed that the difference between the Standard Error of Difference (SED) in mean length of hospital stay was high among URSL treatment group followed by ESWL and PCNL groups, which was statistically significant at $95 \%$ of confidence limits and at 87 degrees of freedom as per Analysis of Variance Test $(p<0.05)$.[13]

\section{Retreatment Rate}

The retreatment rate for upper ureteral stone irrespective of the size of the stone was significantly high $(\mathrm{p}<0.019)$ with ESWL treatment group (33.33\%) followed by URSL and PCNL treatment groups with $13.33 \%$ and $6.67 \%$ respectively. And we also observed that high prevalence of conservative or spontaneous $(10 \%)$ and additional surgical procedures (23.33\%) were done within ESWL treatment group than other treatment groups. Similar results were shown by Lam JS, Greene TD et al, i.e. said that a subsequent intervention for the stone using the initial treatment was higher in ESWL patients than URSL (RR 6.18, 95\%, CI 3.68 to 10.38).[11]

\section{Post-Operative Complications}

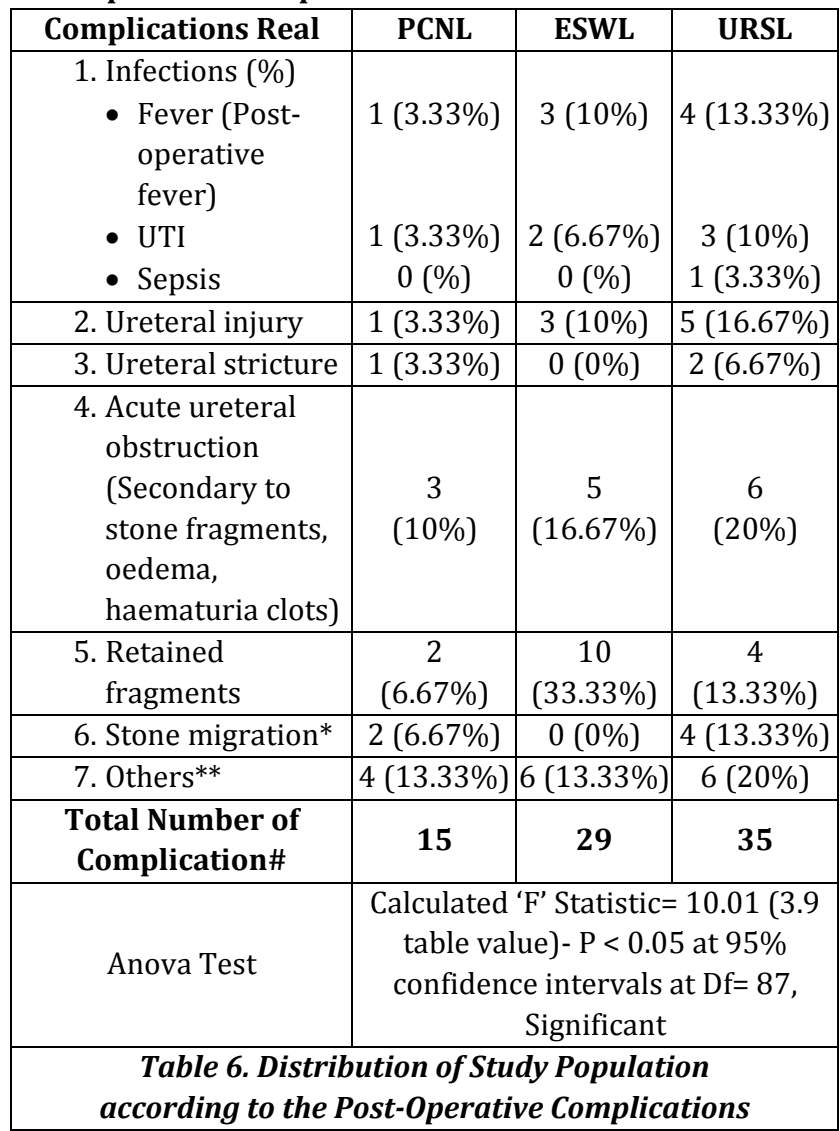

*Migration into ureter and kidney in PCNL and URSL procedures respectively.

**Retention of urine, bleeding, stein stressae, etc. \#Multiple answers.

The above Table No. 6 shows that significantly highest number $(\mathrm{n}=35)$ of post-operative complications were observed among the URSL treatment group than others $\{($ Analysis of Variance Test $=10.01(\mathrm{p}<0.05)$ at $95 \% \mathrm{CF}$ and $87 \mathrm{DF}\}$. And the retained ureteral stone fragments were high among ESWL group with $33.33 \%$ and the complication with acute ureteral obstruction high among URSL group (20\%) followed by ESWL group (16.67\%) and PCNL group (10\%). And post-operative fever was also observed to be high among
URSL (13.33\%) followed by ESWL group (10\%) and PCNL (3.33\%).

And highest numbers of complications (35) were observed among the URSL treatment groups followed by ESWL and PCNL treatment groups with 29 and 15 complications. This observed difference was statistically significant at $95 \%$ of confidence limits and at $87 \mathrm{df}$, on ANOVA test (F statistic $=10.01, p<0.05$ ). Same was observed by Parker BD and his colleagues and also by other studies.[12][13][14]

\section{CONCLUSION}

1. The Institutional based study has shown $35 \%$ prevalence of the renal calculi, out of which about $75.71 \%$ of them were of proximal ureteral calculi.

2. And upper ureteral calculi was more than twice in men than the female population.

3. The PCNL and URSL acceptors were significantly high among < 40 years' age group, whereas ESWL acceptors were high among 40 or more years' age group.

4. And PCNL treatment acceptors were significantly more from upper socio-economic class and 10th and above studied population.

5. More number of surgical treatment acceptors belonged to professional, semi-skilled occupations and among who consume non-vegetarian daily or $3-5 /$ week, but less in who do physical exercise daily or 3 - 5 days/week.

6. Prevalence of comorbidities among three study groups was $38.89 \%$. And the renal failure prevalence was $31.11 \%$.

7. Overall stone free rate on initial treatment irrespective of the stone size was significantly high $(p<0.019)$ in PCNL treatment group than others.

8. Retreatment rate irrespective of the size of the stone was significantly high $(\mathrm{p}<0.019)$ with ESWL treatment group than others.

9. High prevalence of conservative or spontaneous $(10 \%)$ and additional surgical procedures $(23.33 \%)$ were done within ESWL treatment group than other groups.

10. Mean cost of PCNL treatment was found higher than ESWL and URSL treatment groups ( $p>0.05$ ).

11. There was a significant difference in mean length of hospital stay between URSL, ESWL and PCNL $(\mathrm{p}<0.05)$.

12. Significantly highest numbers of complications were observed among the URSL group than other groups $(\mathrm{p}<$ 0.05). Whereas retained ureteral stone fragments were high in ESWL group with 33.33\%.

13. Acute ureteral obstruction was high among URSL group (20\%) followed by ESWL group (16.67\%) and PCNL group (10\%).

After all above observations, we can conclude that PCNL treatment is the best method because it has highest level of stone free rate and less number of complications, even though duration and cost of the PCNL treatment was higher than the ESWL and URSL treatment procedures. But we cannot generalise these results with the standard population, because the present study was done in a single Institute with small sample and short-term followup period and the results can also depend upon the surgeon skills, equipment available in that hospital too. 


\section{Recommendations}

To conduct an extensive study in multiple centres of India to throw more light on outcome of available treatments and the existing barriers thereby.

Reducing the morbidity by treating the patients and educating the high-risk population with the cost benefit treatment methods and cost effective health educational sessions.

\section{Justification of the Study}

While searching for the review we did not find much literature which is related to Indians, especially from Telangana state. Hence, we conducted this study to assess the prevalence, risk factors of urolithiasis. And we compared the outcome of the treatment procedures available in our hospital, so as to advice the patient to choose the best method for fast relief with minimum expenditure and complications. Modern techniques of calculi removal are Ureteroscopy (URSL), Percutaneous Nephrolithotomy (PCNL) and Extracorporeal Shock Wave Lithotripsy (ESWL).

\section{Limitations of the Study}

1). Because of time and financial constraints, we were not able to conduct this study in a large and enough sample population. And it was a single institutional based and shortterm followup study. Hence, the results cannot be interpreted with the whole population. 2). In the study period, there were almost nil standard comparative studies of PCNL, ESWL and URSL treatment procedures with similar objectives in Indian scenario, hence we had limitation in discussion of our study results.

\section{ACKNOWLEDGEMENT}

First, I wish to acknowledge my sincere thanks to the renal or ureteral stone patients, those who have given the consent to take part in our study and also the hospital market yard chairman, those who gave the permission to conduct a medical camp to examine the children and to apply my study tool to gather the required information. Finally, I want to thank my baby for the support she has given me to complete my work.

\section{REFERENCES}

[1] Menon M, Parulkar BC, Drash GW, et al. Urinary lithiasis: etiology, diagnosis, diagnosis and management. In: Walsh PC. edr. Campbell's Urology. $7^{\text {th }}$ edn. Philadelphia: Saunders 1998:2661-733.
[2] Wilkinson H. Clinical investigation and management of patients with renal stones. Ann Clin Biochem 2001;38(pt 3):180-7.

[3] Bihl G, Meyers A. Recurrent renal stone diseaseadvances in pathogenesis and clinical management. Lancet 2001;358(928):651-6.

[4] Stamatelou KK, Francis ME, Jones CA, et al. Time trends in reported prevalence of kidney stones in the United States: 1976-1994. Kidney Int 2003;63(5):1817-23.

[5] Parks JH, Barsky R, Coe FL. Gender differences in seasonal variation of urine stone risk factors. J Urol 2003;170(2 Pt 1):384-8.

[6] Preminger GM, Hans-Göran T, Assimos DG, et al. 2007 Guideline for the management of ureteral calculi. The J Urology 2007;178(6):2418-34.

[7] Tiselius HG, Ackermann D, Alken P, et al. Guidelines on urolithiasis. Eur Urol 2001;40(4):362-71.

[8] Kumar V, Ahlawat R, Banjeree GK, et al. Percutaneous ureterolitholapaxy: the best bet to clear large bulk impacted upper ureteral calculi. Arch Esp urol 1996;49(1):86-91.

[9] Maheshwari PN, Oswal AT, Andankar M, et al. Is antegrade ureteroscopy better than retrograde ureteroscopy for impacted large upper ureteral calculi? J Endourol 1999;13(6):441-4.

[10] Goel R, Aron M, Kesarwani PK, et al. Percutaneous antegrade removal of impacted upper-ureteral calculi: still the treatment of choice in developing countries. J Endourol 2005;19(1):54-7.

[11] Lam JS, Greene TD, Gupta M. Treatment of proximal ureteral calculi: holmium: YAG laser ureterolithotripsy versus extracorporeal shock wave lithotripsy. J Urol 2002;167(5):1972-6.

[12] Parker BD, Frederick RW, Reilly TP, et al. Efficiency and cost of treating proximal ureteral stones: shock wave lithotripsy versus ureteroscopy plus holmium: yttrium-aluminum-garnet laser. Urology 2004;64(6):1102-6.

[13] Tawfiek ER, Bagley DH. Management of upper urinary tract calculi with ureteroscopic techniques. Urology 1999;53(1):25-31.

[14] Segura JW, Preminger GM, Assimos DG, et al. Ureteral stones clinical guidelines panel summary report on the management of ureteral calculi. The American Urological Association 1997;158(5):1915-21. 